\title{
Carola Saavedra - Com armas sonolentas. Um romance de formação
}

\author{
Carola Saavedra - Com armas sonolentas. Um romance de formação \\ Carola Saavedra - Com armas sonolentas. Um romance de formação
}

AUTOR

\section{Aline Teixeira da} Silva Lima

alinetslima@

hotmail.com

* Doutoranda em Literatura pela

Universidade de Brasília (UnB, Brasil).

\section{Saavedra, C (2018). Com armas sonolentas, Um romance de formação. São Paulo: Companhia} das Letras.

RESUMO:

A obra de Carola Saavedra, Com armas sonolentas, Um romance de formação, publicada pela editora Companhia das Letras (2018), cujo título é inspirado em um verso da poeta e freira mexicana Juana Inés de la Cruz, morta em 1695, artista fundamental para o feminismo e a literatura latino-americana, narra a vivência de três mulheres, as quais se inter-relacionam por suas genealogias, no entanto, possuem histórias de vida e identidades muito distintas, marcadas por uma constante sensação de incompletude. A obra de Saavedra é um marco sobre mulheres profundas, fortes e sonhadoras, mas que, ao mesmo tempo, não compreendem seus lugares no mundo.

\section{RESUMEN:}

El libro de Carola Saavedra, Com armas sonolentas, Um romance de formação, publicado por la editorial Companhia das Letras (2018), cuyo título está inspirado en un verso de la poeta y monja mexicana Juana Inés de la Cruz, que murió en 1695, una artista clave para el feminismo y la literatura latinoamericana, narra la experiencia de tres mujeres, que están interrelacionadas por sus genealogías, sin embargo, tienen historias e identidades de vida muy diferentes, marcadas por un sentimiento constante de incompletitud. El trabajo de Saavedra es un hito sobre las mujeres profundas, fuertes y soñadoras que, al mismo tiempo, no entienden su lugar en el mundo.

\section{ABSTRACT:}

Carola Saavedra's book, Com armas sonolentas, Um romance de formação, published by the publishing company Companhia das Letras (2018), whose title is inspired by a verse by the Mexican poet and nun Juana Inés de la Cruz, dead in 1695, a key artist for feminism and Latin American literature, narrates the experience of three women, who are interrelated by their genealogies, however, they have very different life histories and identities, marked by a constant sense of incompleteness. Saavedra's work is a milestone about deep, strong and dreamy women who, at the same time, do not understand their places in the world.. 
De acordo com Regina Dalcastagnè, "as mulheres [escritoras] constroem uma representação feminina mais plural e mais detalhada, incluem temáticas da agenda feminista que passam despercebidas pelos autores homens e problematizam questões que costumam estar mais marcadas por estereótipos de gênero" (2010, p. 58). Tal afirmativa se dá na mais recente obra de Carola Saavedra', intitulada Com armas sonolentas, Um romance de formação, a qual enfoca justamente as temáticas do feminino: violência doméstica, abuso sexual e, principalmente, maternidade e relação entre mães e filhas.

A ideia para o enredo do livro surgiu em uma exposição da artista plástica ítalo-brasileira Anna Maria Maiolino, onde, em uma fotografia, mãe, filha e avó apareciam ligadas por um fio. Em uma entrevista ${ }^{2}$, a autora revelou que "estava muito preocupada em falar de mulheres, de temas como mãe e filha, raro de aparecer na literatura escrita por mulheres. Queria falar dessa relação tão difícil e delicada, sobre questões do feminino".

Assim, o romance polifônico narra a história de três mulheres de uma mesma família, porém em tempo e espaço diferentes. Este é dividido em duas partes: "O lado de fora", que apresenta a história dessas personagens de uma maneira mais individual, apesar do inevitável entrelaçamento entre elas, e "O lado de dentro", que aproxima e re(conecta) a vida destas. Cada uma dessas partes é composta por três capítulos, que recebem como título o nome da personagem (ou um indicativo de sua identidade), cuja história será contada: Anna, Maike e Avó.

\section{Anna}

Anna, uma atriz não muito conhecida, é a primeira personagem apresentada ao leitor. O seu maior desejo é apagar sua origem, principalmente no que tange à sua mãe, pois, segundo ela, "não queria ser filha de um cão escorraçado" (Saavedra, 2018, p. 171), e se tornar uma celebridade mundial. Por essa razão, ao conhecer um diretor de cinema alemão, ela se casa dois meses depois, mesmo sem amor, e se muda para a Alemanha, com a esperança de reescrever sua história de vida.

Entretanto, essa fuga de sua identidade Ihe trouxe ainda mais sofrimento, pois passou a morar em um país estranho, incapaz de se comunicar em alemão e confinada em casa, já que o marido estava sempre viajando a trabalho. Em meio a essas vicissitudes, ela engravida, mas, ao contrário "dos discursos recorrentes sobre as mulheres, que lhes atribuem o papel de mãe, já normatizado e fixado em torno da noção do instinto materno, que serve para a naturalização dos papéis de gênero" (Dalcastagnè, 2010, pp. 61-62), a autora desconstrói esse estigma de que "a maternidade seria seu destino [das mulheres] e sua única forma de transcendência" (Swain, 2007, p. 207), visto que a personagem rejeita, desde o início, essa gravidez e, mesmo depois do nascimento da filha, o senso maternal não Ihe aflora.

Desse modo, em um parque na Alemanha, ela abandona o bebê e regressa ao Brasil. Depois de vários anos, de volta ao Rio de Janeiro, em uma peça autobiográfica, no teatro Centro Cultural, Anna conjetura como teria sido sua vida, caso não houvesse repelido a filha, agora uma mulher já adulta, e tivesse exercido efetivamente o papel de mãe. Contudo, embora havendo tido aproximadamente duas décadas para refletir sobre seus feitos, não há arrependimento, demonstrando que que tanto seu corpo quanto sua mente não se encaixam na lógica patriarcal quanto ao destino "natural" da mulher de se tornar mãe.
PALAVRAS-CHAVE Maternidade; romance

brasileiro; Carola Saavedra; gênero.

PALABRAS CLAVE Maternidad; novela brasileña; Carola Saavedra; género.

KEYWORDS

Maternity;

Brazilian romance;

Carola Saavedra; gender.

Recibido:

21/10/2019

Aceptado:

$15 / 04 / 2020$ 
Segundo Cristina Maria Stevens, a ficção contemporânea "tem articulado a temática da gestação, parto e maternação a partir da perspectiva da mulher, algumas vezes de forma idealizada, ou formas que perpetuam a equação mulher/mãe, mas apresentando também outras construções discursivas para novas imagens de mãe" (2007, p. 46). Todavia, Saavedra vai além, pois, por meio de Anna, ela não representa apenas uma nova imagem de mãe, mas sim uma mulher que nega, sem culpa, qualquer associação com esse papel, descontruindo completamente o mito de a felicidade da mulher estar atrelada ao seu ventre.

\section{Maike}

No capítulo seguinte, a relação entre mãe e filha é novamente explorada, porém, a partir de uma outra perspectiva. A protagonista da história agora é Maike, uma jovem alemã, que desde pequena não se sentia parte de sua família. Mesmo que a conexão entre as personagens não seja evidente, uma leitura atenta permite que o leitor identifique rapidamente tais relações familiares, constatando que Maike é a filha que Anna abandonou em solo alemão.

Conforme os psicólogos Dornelas e Garcia, "as mulheres mantêm a identificação com a mãe ao longo da vida, o que Ihe ajuda na construção da própria identidade. Por outro lado, a mãe também se identifica com a filha e projeta seus sentimentos nela em busca de identificação" (2006, p. 334). Entretanto, essa via de mão dupla não está presente na relação de Maike e sua mãe, pois, mesmo desconhecendo suas origens, visto que não fazia ideia de que era adotada, ela dizia ter

um sentimento que, na presença da minha mãe, se transformava em raiva, em ódio. Eu a culpava de alguma coisa, mas não sabia do quê. Havia algo em mim, eu sempre tivera essa impressão, desde pequena, que destoava daquele mundo, daquela falsa tranquilidade (Saavedra, 2018, p. 73).

Ou seja, apesar de a mãe buscar essa paridade com a filha, chegando até a exercer um extremo controle sobre ela, como demonstra o fato de ela haver escolhido a carreira profissional que Maike deveria seguir, que seria a de advogada, assim como ela, Maike não se identifica em nada com aquela mulher e refuta suas idealizações para a vida dela.

Em razão desse sentimento de ausência de pertencimento, ela acaba desfazendo, gradativamente, o vínculo com a mãe adotiva. Primeiramente, ela se desvia da profissão que sua figura materna desejava que ela seguisse e se matricula no curso de Língua Portuguesa, aparentemente, por puro acaso, já que não têm ciência de sua filiação brasileira.

Depois, ela se descobre homossexual, começa a namorar uma colega do curso e decide morar sozinha, saindo, então, da casa dos pais. E, por fim, ela se inscreve em um programa de intercâmbio no Brasil, passando a viver no Rio de Janeiro, se aproximando de sua verdadeira origem e se afastando, desse modo, por completo da mãe adotiva. Para ela,

a sensação de viver em uma língua estrangeira, era tornar-se, mesmo que sutilmente, outra pessoa. No me caso meu caso essa pessoa (...) me parecia muito mais próxima de mim do que a que vivia na Alemanha, como se em português eu me tornasse quem eu realmente era (Saavedra, 2018, p. 217).

Percebe-se em Maike, portanto, um "devir- mulher" (Deleuze, 1997), pois ela é uma mulher inacabada, em constante processo de (trans)formação, que não se permite engessar pelos conceitos binários de gênero e sexualidade, nem pelo essencialismo identitário. 


\section{Avó}

A última história é a da personagem que pode ser considerada o fio condutor entre as demais, a da avó, a qual não é nomeada em nenhum momento do texto. Ela, na verdade, é a avó de Maike e, por conseguinte, a mãe de Anna. Ainda adolescente, ela foi obrigada pela própria mãe a abandonar a família em Minas Gerais e seguir rumo ao Rio de Janeiro, onde trabalharia, como empregada doméstica, na residência de uma família de classe média alta no bairro de Copacabana.

Lá, ela é violentada sexualmente pelo filho de Dona Clotilde, sua patroa, e o estupro resulta em uma gravidez. Ao saber da gestação, a dona da casa a insulta e a culpa pelo acontecido, entretanto, aceita que ela continue morando com sua família e junto a eles crie a criança, desde que nunca revele a verdadeira identidade do pai. Apesar das circunstâncias da concepção, a jovem se alegra com a gravidez, tanto que queria que sua "barriga ficasse cada vez maior, até sair esse filho de dentro dela, esse filho que era tudo o que ela tinha" (Saavedra, 2018, p. 148).

Dessa forma, Anna nasce e é criada como afilhada de Dona Clotilde. Contudo, ainda que a mãe de Anna Ihe desse muito amor, com o passar do tempo, ela se sente desconfortável no entre-lugar onde vivia, pois estava dividida entre a vida abonada que seus padrinhos lhe proporcionavam, por um lado, e o pouco, no sentido material, que a mãe podia oferecer-lhe, por outro. Além disso, a simplicidade e a ignorância da progenitora a incomodam e envergonham, gerando uma crise entre as duas:

Eu não quero ser sua filha, eu tenho vergonha de você, do seu rosto que é só osso, dos seus cabelos grudados na cabeça, dos dentes que faltam na sua boca, as suas unhas todas roídas, você parece uma velha, uma mendiga, e eu não quero ser sua filha, não quero ser filha da empregada, eu queria ser filha da dinda (...), a filha chorava, e ela sentiu vontade de nunca ter existido (Saavedra, 2018, p.158).

Observa-se, portanto, que nas três histórias, porém por vieses distintos, a escrita dá centralidade à temática da maternidade. Lélia Almeida (2003, 2004), em suas reflexões sobre a representação de genealogias femininas na escrita de autoria feminina, afirma que a representação da relação entre mães e filhas, nesse tipo de texto, é sempre complexa e particular. Ela chama a atenção

para a importância dos afetos femininos - desde as genealogias mais próximas, como mães, avós, bisavós, filhas e netas, como madrinhas, amigas, tias, irmãs, etc. - na existência das mulheres, havendo também uma tensão natural existente nessas relações entre a necessidade de uma simbiose e a necessidade de uma ruptura, tensão permanente ao longo da biografia das mães e das filhas que constroem e estruturam dessa maneira, suas personalidades (Almeida, 2003, s. p.).

Tanto a tensão como a necessidade de ruptura mãe/filha se passa, de alguma maneira, com as três protagonistas, sendo que com Anna e sua mãe esse relacionamento é marcado por uma natureza dialética, integrando separação e aproximação, quando a mãe já se encontrava idosa. Assim, a narrativa expõe os conflitos de uma linhagem matrilinear, em que as tensões entre mães e filhas acabam por proporcionar, no caso de Anna e sua mãe, dentre outros aspectos, o afeto.

Ademais, por ser um romance de formação, como aponta o próprio título, é possível acompanhar essa genealogia feminina não apenas no processo de viver e amadurecer, deixando a infância e a adolescência para trás e se tornando mulheres, é possível observar também a busca por autoconhecimento, a vontade de se sentirem parte de algo, de descobrirem sua própria história. Assim, este potente romance discute as questões intrínsecas à maternidade e as relações de afeto mãe/filha, expondo temáticas ainda silenciadas na literatura nacional e instigando questionamentos e ponderações sobre os discursos de "instinto materno", os quais ainda vigoram na sociedade atual. 
- CAROLA SAAVEDRA - COM ARMAS SONOLENTAS. UM ROMANCE DE FORMAÇÃO •

ALINE TEIXEIRA DA SILVA LIMA

\section{NOTAS}

1 Também da autora: Toda terça (2007), Flores azuis (2008), Paisagem com dromedário (2010) e O inventário das coisas ausentes (2014).

2 Entrevista ao Correio Braziliense. Recuperado de [http://blogs.correiobraziliense.com.br/leiodetudo/novoromance-de-carola-saavedra/]. Consultado [10-102019]. 


\section{REFERÊNCIAS BIBLIOGRÁFICAS}

Almeida, L. (2003). Genealogias femininas em O penhoar chinês de Rachel Jardim. Espéculo: Revista de Estudios Literários, Universidad Complutense de Madrid, $\mathrm{n}^{\circ} 24$. Recuperado de [https://webs.ucm.es/info/especulo/ numero24/genealog.html]. Consultado [10-10-2019].

Almeida, L. (2004). Linhagens e ancestralidade na literatura de autoria feminina. Espéculo: Revista de Estudios Literários, Universidad Complutense de Madrid, $\mathrm{n}^{\circ}$ 26. Recuperado de [https://webs.ucm.es/ info/especulo/numero26/linhages.html]. Consultado [1010-2019].

Dalcastagnè, R. (2010). Representações restritas: a mulher no romance brasileiro contemporâneo. In R. Dalcastagnè \& V. M Leal Vasconcelos (Org.). Deslocamentos de gênero na narrativa brasileira contemporânea. São Paulo: Horizonte.

Deleuze, G. (1997). A literatura e a vida. Crítica e clínica. São Paulo: Editora 34.

Dornelas, K. C. A., \& Garcia, A. (2006). O relacionamento entre mãe e filha adulta: um estudo descritivo. Interação em Psicologia, 10(2), s. p..

Stevens, C. (2007). Maternidade e feminismo: diálogos na literatura contemporânea. In C. Stevens (Org.). Maternidade e feminismo: diálogos Interdisciplinares. Florianópolis: Editora Mulheres.

Swain, T. (2007). Meu corpo é um útero? Reflexões sobre a procriação e a maternidade. In C. Stevens (Org.). Maternidade e feminismo: diálogos Interdisciplinares. Florianópolis: Editora Mulheres. 